\title{
DOE/PC/89908-T/8
}

$\mathrm{DOE} / \mathrm{PC} / 89908--\mathrm{Tl} 8$

DE92 009998

QUARTERLY TECHNICAL PROGRESS REPORT NO. 9

OCTOBER - DECEMBER 1991

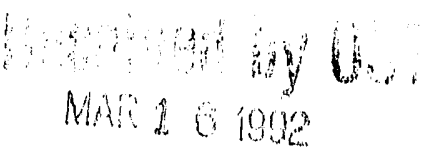

\section{ENGINEERING DESIGN AND ANALYSIS OF ADVANCED PHYSICAL \\ FINE COAL CLEANING TECHNOLOGIES}

for

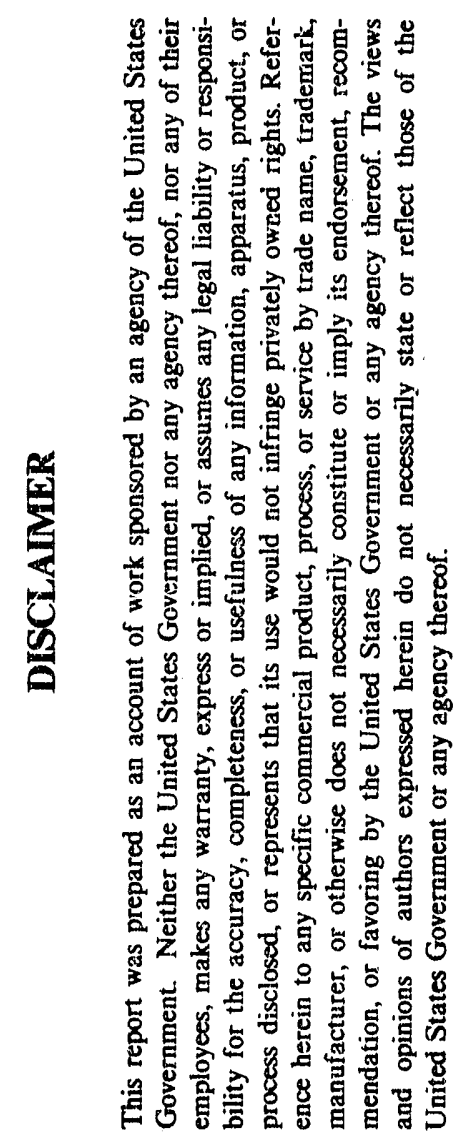

\author{
U.S. DEPARTMENT OF ENERGY \\ PITTSBURGH ENERGY TECHNOLOGY CENTER \\ PITTSBURGH, PA
}

CONTRACT NO. DE-AC22-89PC89908

SUBMITTED BY

P.W. GALLIER

PROJECT MANAGER

ASPEN TECHNOLOGY, INC.

251 VASSAR STREET

CAMBRIDGE, MA 02139

JANUARY 20, 1992 
TABLE OF CONTENTS

Page

1.0 INTRODUCTION

2.0 ADMINISTRATIVE ITEMS 2

3.0 TASK 1.2 - Enginefring Analysis of Conventional 3 Coarse Coal Cleaning

3.1 Planned Scope of Work 3

3.2 Technical Status 3

3.2.1 Model Testing and Validation 3

3.2.2 Flowsheet Water Balance 4

3.2.3 ASPEN PLUS ${ }^{\text {TM }}$ System Implementations

3.2.4 Sizing and Costing of Ancillary 5

3.2.5 Miscellaneous Items 6

4.0 TASK 1.3 - Engineering Analysis of Unit Operations 7 for Processing Fine and Ultrafine Coals

TASK 1.4 - Engineering Analysis of Advanced Technologies for Physical Cleaning of Fine and Ultrafine Coals

5.0 QUARTER NO. 10 WORK PLAN

APPENDIX 


\subsection{INTRODUCTION}

This project is sponsored by the United States Department of Energy (DOE) for the "Engineering Design and Analysis of Advanced Physical Fine Coal Cleaning Technologies:. The major goal is to provide the simulation tools for modeling both conventional and advanced coal cleaning technologies. This DOE project is part of a major research initiative by the Pittsburgh Energy Technology Center (PETC) aimed at advancing three advanced coal cleaning technologies - heavy-liquid cylconing, selective agglomeration, and advanced froth flotation through the proof-of-concept (POC) level.

The commercially available ASPEN PLUS process simulation package will be extended to handle coal cleaning applications. Algorithms for predicting the process performance, equipment size, and flowsheet economics of commercial coal cleaning devices and related ancillary equipment will be incorporated into the coal cleaning simulator.

This report is submitted to document the progress of Aspen Technology, Inc. (AspenTech), its contractor, ICF Kaiser Engineers, Inc., (ICF KE) and CQ Inc., a subcontractor to ICF KE, for the ninth quarterly reporting period, october through December 1991. ICF KE is providing coal preparation consulting and processing engineering services in this work and they are responsible for recommending the design of models to represent conventional coal cleaning equipment and costing of these models. 


\subsection{ADMINISTRATIVE ITEMS}

Aspentech, along with its subcontractors, ICF KE and CQ Inc., participated in a project review meeting with DOE on November 7, 1991 at the AspenTech offices in Cambridge. At this meeting, AspenTech, ICF KE, and CQ Inc. presented the results of the plant validation simulations begun in october. The remaining issues to be addressed in Task 2, model selection for Tasks 3 and 4 , and the Task 6 work were also discussed. On November 8, a meeting was held between AspenTech and ICF $\mathrm{KE}$ concerning the problems found in water balances in flowsheet simulations.

A PC version of the Coal Cleaning Simulator with ModelManager ${ }^{\text {TM }}$ interface was shipped to DOE the first week of December 1991.

At the end of December, AspenTech proposed a subcontract amendment for the addition of Task 6 to ICF KE. After review of the amendment, ICF KE declined the additional work due to the change in rate structure proposed. 
3.0 TASK 1.2 - Engineering Analysis of Conventional Coarse Coal Cleaning

\subsection{Planned Scope of Hork}

The work plan for this quarter called for the completion of all Task 2 items including model documentation, testing, and validation. Tasks 3, 4, and 6 were also scheduled to begin.

\subsection{Technical Status}

In this section the status of Task 2 issues addressed during the quarter will be discussed.

\subsubsection{Model Testing and Validation}

Validation studies for the Task 2 coal cleaning models continued throughout the quarter with the simulation of six flowsheets.

Four flowsheet validations are being completed by ICF KE and CQ Inc. Draft reports for these validations are being prepared and are now undergoing internal review. The major unit operations contained in these flowsheets are as follows.

Flowsheet No. 1 - Heavy-media vessel / Heavy-media cyclone / Water-only cyclone

Flowsheet No. 2 - Jig / Froth flotation

Flowsheet No. 3 - ieavy-media cyclone / Water-only cyclone

Flowsheet No. 4 - Heavy-media vessel / Heavy-media cyclone / Water-only cyclone / Froth flotation

Several problems were encountered in the simulation of these flowsheets, and in many cases have been corrected. A summary of findings from these four validations may be found in Tables 1-4 of the Appendix to this report. These tables show total plant yields and total plant clean coal ash, sulfur, and $B t u / 1 b$, and results for the major unit operations for each flowsheet. The simulation results are compared to data from performance studies or from design flowsheets. In general they provide a very good approximation. One case of poor approximation is that of the froth flotation model in flowsheet number four. Enhancements will be made to this model as Jask 6 test data becomes available. Actual plant feed washabilities were used for all these flowsheet simulations. 
Aspentech is completing two of the six flowsheet validations. The first flowsheet consists of forty seven unit operations, the most important being two heavy media cyclones, a heavy media vessel, and a froth flotation unit. The second consists of forty five unit operations including two heavy media vessels, a fine coal jig, a froth flotation unit, and two roll crushers. The actual plant feed washabilities for these flowsheets was not available in a form which could be readily utilized in the simulator. However, a number of simulation runs made with washabilities similar to the actual data revealed problems in the water balance around certain unit operations. These problems are identical to those found at the ICF $\mathrm{KE}$ and $\mathrm{CQ}$ Inc. testing installations; the approach used for correcting them are discussed below.

Simulations of these two flowsheets with actual plant feed washability will begin starting in January with the addition of the new interpolation algorithms. The draft validation reports will also be started at that time.

\subsubsection{Flowsheet Water Balance}

A meeting was held between AspenTech and ICF KE concerning problems found in flowsheet water balance. In most cases the problems arose when moisture in the feed to a unit operation exceeded the water requirements for that device. As a result, models which determine the make-up water needed calculated a negative flowrate for this stream. The model algorithms were re-written to pass the excess water through the unit and distribute it between the output streams. This change was made to all the gravity models.

Changes were also made to the centrifuges (vibrating basket, EB, solid bowl, and screen bowl). The modifications involved the calculation of specific gravity of solids and the separation size for solids loss. In the specific gravity of solids calculation, a coding error was corrected. As for separation size, the calculation of this value was reformulated to be associated with the bottom size of the feed to the device.

Another correction involving water balance calculations is underway and involves the prediction of screen oversize moisture content. Professor Hogg of Penn State University has submitted an algorithm using gravity dewatering principles as an alternate method to the current one which utilizes an equation regressed from data published by Allis-Chalmers corporation. the new algorithm has been programmed and is currently being tested.

\subsubsection{ASPEN PLUS ${ }^{\text {Th }}$ System Implementations}

The new interpolation algorithm completed during the previous quarter was extensively tested in a series of plant simulations. one problem was found in the simulations when washability was manually inputted instead of being retrieved from the Coal Databank. 
This is due to the fact that washability data from these two sources are stored in different memory locations. The problem was corrected and the modified interpolation routines were added to the simulator. The new interpolation method will be made available at all coal cleaning Simulator installations with the next delivery.

Other changes made consisted in implementing the correction to the water balance calculations discussed previously, and the addition of an input echo mechanism to the coal cleaning models. The user may now request the echo of input data as part of the model report.

\subsubsection{Sizing and Costing of Ancillary Equipment}

ICF KE compiled algorithms for standard ancillary unit operations found in a coal preparation flowsheet. These unit operations are mostly related to raw coal, clean coal, and refuse handling and storage.

In order for these devices to be used in the simulator, no performance or process prediction is needed. However, an algorithm is required to size the equipment for the coal flowrate and other user-supplied data. The information given below summarizes the approach to be used for the sizing calculations.

Coal Receiving - A ROM coal receiving bin is sized based on the capacity of a truck delivering coal to the bin multiplied by two.

- Outside Storage - The model for conical pile outside storage requires the user to input the number of storage hours needed. This number is multiplied by the feed tons per hour to determine the total tons required for stcrage. The bulk density of the coal is determined and used along with the tons to calculate the radius and height of the pile.

- Inside Storage - As with outside storage, the silo storage sizing model requires the user to input storage hours. This is again multiplled by feed flowrate to determine the total tons required for storage. The total tons and bulk density of the coal are then used to calculate a required storage volume. the calculated volume is them matched to a standard silo diameter and height.

Additional sizing models for refuse loadout, unit train loadout, vibrating feeders, centrifugal pumps, and magnetic separators have been developed and are currently under internal testing and review. Their algorithms will be discussed once the approach has been validated.

Aspen rechnology, Inc. / 1-20-92 / DE-AC22-89PC89908

Engineering Design and Analysis of Advanced Physical Fine Coal Cleaning Technologies 


\subsubsection{Miscellaneous Items}

Topical reports for gravity separation and size classification models are currently being drafted and are estimated to be 60 percent complete. 
4.0 TASK 1.3 - Engineering Analys is of Unit Operations for Processing Fine and
Ultrafine Coals TASK 1.4 - Engineering Analys is of Advanced Technologies for Physical cleaning of Fine and Ultrafine Coals

A 1 ist of models for Tasks 3 and 4 was presented at the review meeting held on November 7 th. Model selection for the advanced cycioning and selective agglomeration categories will be finalized by DOE. 
5.0 QUARTER NO. 10 - WORK PLAN

- Complete Task 2 models

- Complete Task 2 model documentation

- Complete Task 2 model testing and validation

- Continue Task 3 and 4 
APPENDIX

QUARTERLY TECHNICAL PROGRESS REPORT NO. 9

OCTOBER - DECEMBER 1991

ENGINEERING DESIGN AND ANALYSIS OF ADVANCED PHYSICAL

FINE COAL CLEANING TECHNOLOGIES

for

U.S. DEPARTMENT OF ENERGY

PITTSBURGH ENERGY TECHNOLOGY CENTER

PITTSBURGH, PA

CONTRACT NO. DE-AC22-89PC89908 
Table 1. Validation Testing: Flowsheet No. I Results Comparison

\begin{tabular}{|c|c|c|}
\hline FLOWSHEET NO. 1 & PLANT & SIMULATOR \\
\hline \multicolumn{3}{|c|}{ Total Plant } \\
\hline Clean Coal Yield & 77.20 & 68.28 \\
\hline Clean Coal Ash & 9.54 & 10.32 \\
\hline Clean Coal sulfur & 4.71 & 5.02 \\
\hline Clean Coal Btu/lb & 12,922 & 12,850 \\
\hline \multicolumn{3}{|c|}{ Heavy-media Vesse] } \\
\hline Clean Coal Yield & 77.43 & 78.43 \\
\hline Clean Coal Ash & 9.08 & 8.83 \\
\hline Clean Caol Sulfur & $N / A$ & 4.87 \\
\hline Clean Coal Btu/lb & $N / A$ & 13,088 \\
\hline \multicolumn{3}{|c|}{ Heavy-media Cyclones } \\
\hline Clean Coal Yield & 80.59 & 83.02 \\
\hline Clean Coal Ash & 8.69 & 9.32 \\
\hline clean coal sulfur & $N / A$ & 4.80 \\
\hline Clean Coal Btu/lb & $N / A$ & 13,062 \\
\hline
\end{tabular}


Table 2. Validation Testing: Flowsheet No. 2 Results Comparison

\begin{tabular}{|c|c|c|}
\hline FLOWSHEET NO. 2 & PLANT & SIMULATOR \\
\hline \multicolumn{3}{|c|}{ Total Plant } \\
\hline Clean Coal Yield & 55.00 & 51.20 \\
\hline Clean Coal Ash & 15.60 & 14.40 \\
\hline Clean Coal Sulfur & 1.05 & 1.02 \\
\hline Clean Coal Btu/lb & 12,780 & 12,923 \\
\hline \multicolumn{3}{|c|}{ Heavy-media Vessel } \\
\hline Clean Coal Yield & 57.20 & 54.00 \\
\hline Clean Coal Ash & 15.50 & 14.60 \\
\hline Clean Caol Sulfur & 1.03 & 1.02 \\
\hline Clean Coal Btu/lb & 12,733 & 12,893 \\
\hline \multicolumn{3}{|c|}{ Heavy-media Cyclones } \\
\hline Clean Coal Yield & 48.50 & 66.70 \\
\hline Clean Coal Ash & 15.90 & 12.00 \\
\hline Clean Coal Sulfur & 1.04 & 0.86 \\
\hline Clean Coal Btu/lb & 12,613 & 13,180 \\
\hline
\end{tabular}


Table 3. Validation Testing: Flowsheet No. 3 Results Comparison

\begin{tabular}{|c|c|c|}
\hline FLOWSHEET NO. 3 & PLANT & SIMULATOR \\
\hline \multicolumn{3}{|c|}{ Total Plant } \\
\hline Clean Coal Yield & 35.38 & 33.65 \\
\hline Clean Coal Ash & 12.00 & 11.99 \\
\hline Clean Coal sulfur & $N / A$ & 1.89 \\
\hline Clean Coal Btu/lb & $N / A$ & 13,611 \\
\hline \multicolumn{3}{|c|}{ Heavy-media Vessel } \\
\hline Clean Coal Yield & 30.77 & 27.04 \\
\hline Clean Coal Ash & 11.75 & 10.49 \\
\hline Clean Caol Sulfur & $N / A$ & 1.68 \\
\hline Clean Coal Btu/lb & $N / A$ & 13,874 \\
\hline \multicolumn{3}{|c|}{ Heavy-media Cyclones } \\
\hline Clean Coal Yield & 52.31 & 56.92 \\
\hline Clean Coal Ash & 23.14 & 20.36 \\
\hline Clean Coal Suifur & $N / A$ & 3.21 \\
\hline Clean Coal Btu/lb & $N / A$ & 12,076 \\
\hline
\end{tabular}


Table 4. Validation Testing: Flowsheet No. 4 Results Comparison

\begin{tabular}{|c|c|c|}
\hline FLOWSHEET NO. 4 & PLANT & SIMULATOR \\
\hline \multicolumn{3}{|c|}{ Total Plant } \\
\hline Clean Coal Yield & 71.13 & 69.76 \\
\hline Clean Coal Ash & 9.54 & 11.03 \\
\hline Clean Coal Sulfur & 4.71 & 4.80 \\
\hline Clean Coal Btu/7b & 12,922 & 12,744 \\
\hline \multicolumn{3}{|c|}{ Heavy-media Vessel } \\
\hline Clean Coal Yield & 77.16 & 78.43 \\
\hline Clean Coal Ash & 9.08 & 8.83 \\
\hline Clean Caol Sulfur & $N / A$ & 4.87 \\
\hline Clean Coal Btu/1b & $N / A$ & 13,088 \\
\hline \multicolumn{3}{|c|}{ Heavy-media Cyclones } \\
\hline Clean Coal Yield & 80.97 & 83.02 \\
\hline Clean Coal Ash & 8.69 & 9.32 \\
\hline Clean Coal Sulfur & $N / A$ & 4.80 \\
\hline Clean Coal Btu/lb & $N / A$ & 13,062 \\
\hline \multicolumn{3}{|c|}{ Primary WOC } \\
\hline Clean Coal Yield & 87.62 & 61.30 \\
\hline Clean Coal Ash & 45.40 & 30.57 \\
\hline Clean Coal sulfur & 3.73 & 3.85 \\
\hline Clean Coal Btu/lo & $N / A$ & 9,530 \\
\hline \multicolumn{3}{|c|}{ Secondary WOC } \\
\hline Clean Coal Yield & 81.08 & 28.30 \\
\hline Clean Coal Ash & 46.41 & 52.36 \\
\hline clean Coal Sulfur & 9.14 & 4.24 \\
\hline Clean Coal Btu/lb & $N / A$ & 6,097 \\
\hline \multicolumn{3}{|c|}{ Froth Flotation } \\
\hline Clean Coal Yield & 19.90 & 47.46 \\
\hline Clean Coal Ash & 16.49 & 48.40 \\
\hline clean Coal Sulfur & 4.81 & 3.58 \\
\hline Clean Coal Btu/lb & $N / A$ & 6,678 \\
\hline
\end{tabular}



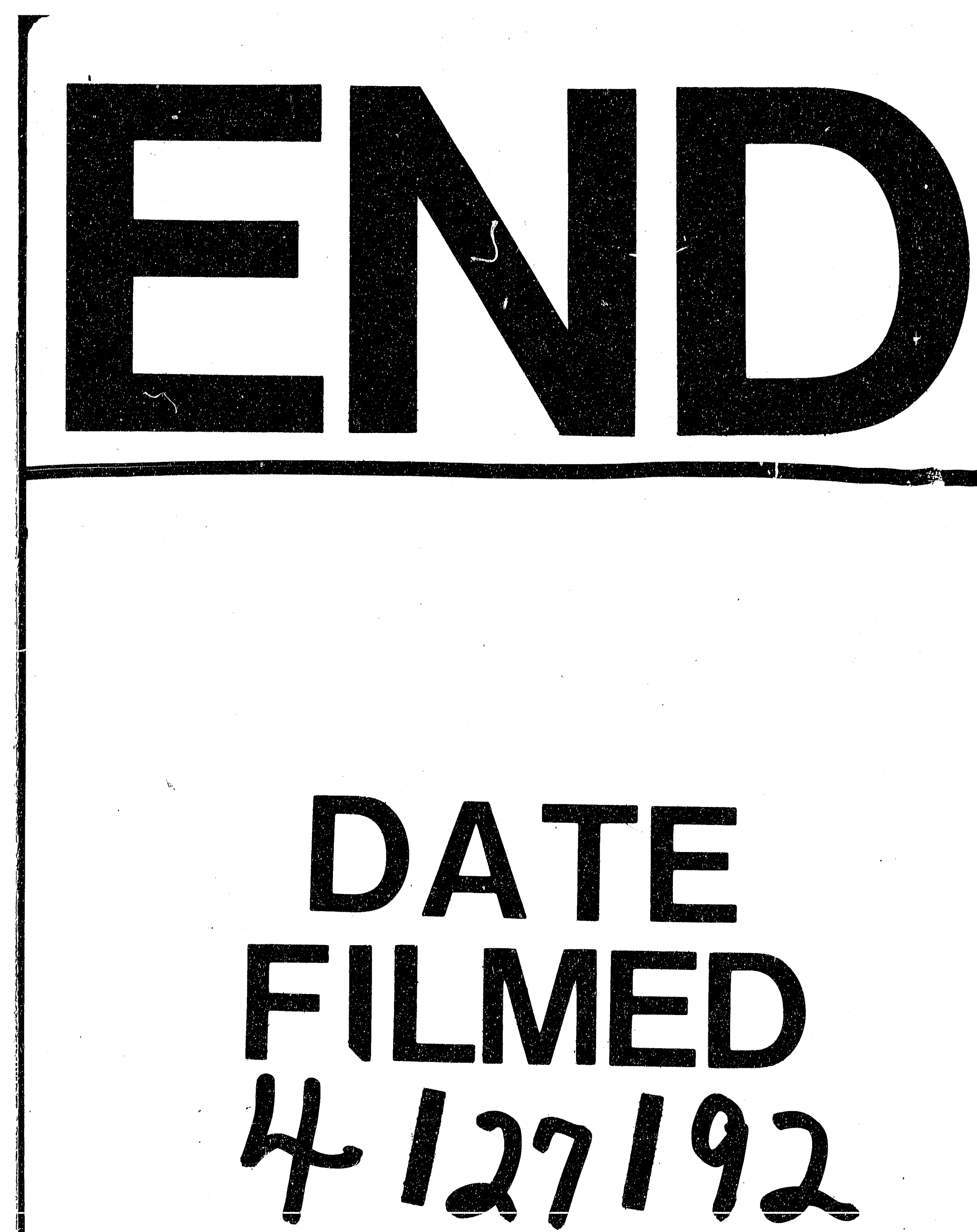
